\title{
Effects of probucol on cultured human umbilical vein endothelial cells injured by hypoxia/reoxygenation
}

\author{
Y.L. Chai, J.Z. Xu, Y.L. Zhang and G.T. Sheng \\ Department of Cardiovascular Medicine, People's Hospital of Jiangxi Province, \\ Nanchang, Jiangxi, China \\ Corresponding author: Y.L. Zhang \\ E-mail: cmu1st_cyl@126.com \\ Genet. Mol. Res. 15 (1): gmr.15016752 \\ Received September 12, 2015 \\ Accepted November 4, 2015 \\ Published March 4, 2016 \\ DOI http://dx.doi.org/10.4238/gmr.15016752
}

\begin{abstract}
There is increasing evidence suggesting that endoplasmic reticulum stress (ERS) plays an important role in the initiation and development of atherosclerosis. This study was designed to examine the effect of probucol on cultured human umbilical vein endothelial cells (HUVECs) injured by hypoxia/reoxygenation $(\mathrm{H} / \mathrm{R})$ and the potential mechanisms involving ERS. Injured HUVECs induced by $\mathrm{Na}_{2} \mathrm{~S}_{2} \mathrm{O}_{4}$ served as an $\mathrm{H} / \mathrm{R}$ model in vitro. The concentration of probucol in this study ranged from 3 to $27 \mu \mathrm{M}$. Cell viability was analyzed using MTT and a lactate dehydrogenase (LDH) assay. The expression of GRP78, X-box-binding protein (XBP)-1, and CHOP (c/EBP-hemologous protein) were quantified using western blot. Compared to cells with H/R injury alone, the results showed that the cell viability increased significantly with probucol, while the LDH leakage rate was significantly lower as analyzed by the LDH assay. Furthermore, the expression levels of GRP78, XBP-1, and CHOP were significantly downregulated. These results indicated that probucol effectively protected HUVEC from injury induced by $H / R$ and that the mechanism might be related to attenuation of ERS.
\end{abstract}

Key words: Probucol; Endoplasmic reticulum stress; Hypoxia/reoxygenation 


\section{INTRODUCTION}

Coronary atherosclerotic heart disease has become one of the highest causes of mortality. How to effectively prevent and treat atherosclerosis (AS) is one of the common hot issues of longterm medical research. Existing studies show that the formation of AS plaque involves multiple cellular mechanisms, including endothelial cell damage, which is an initial factor in vascular disease (Préda et al., 2005; Riwanto and Landmesser, 2013), foam cell formation, and migration of smooth muscle cells (Goldschmidt-Clermont et al., 2012; Chiong et al., 2013; Pirillo et al., 2013; Salisbury and Bronas, 2014). Therefore, the prevention of endothelial cell injury is one of the important goals of vascular disease targeted therapy.

An increasing number of studies show that endoplasmic reticulum stress (ERS) plays a crucial role in ischemia/hypoxia-induced cell injury (Azfer et al., 2006; Minamino and Kitakaze, 2010). Under ischemia/hypoxia, oxidative stress, and other pathological conditions, cells produce a variety of harmful substances that interfere with the normal translation and folding of protein molecules, causing inactivation of these proteins, because the proper folded structure cannot be maintained. Excess unfolded or misfolded proteins deposit in the endoplasmic reticulum, causing ERS, and the protective mechanism of the unfolded protein response (UPR) begins. Thus, the endoplasmic reticulum enhances the function of correctly folded proteins, reduces misfolded protein production, and increases the degradation of misfolded proteins to maintain cellular homeostasis (Pahl, 1999). If the damage is sustained and intense, ERS gradually becomes harmful and initiates an apoptosis mechanism, causing endothelial cell injury and apoptosis (Bredesen et al., 2006; Fairn and Grinstein, 2008), leading to atherosclerosis and other diseases.

In addition to its lipid lowering effect, probucol also has a powerful antioxidant effect. Probucol effectively prevents low-density lipoprotein (LDL) oxidation, thereby reducing the damage to vascular intima by foam cells and scavenging oxygen free radicals, and slowing atherosclerotic plaque progression, which may be related to its antioxidant effect (Schwartz et al., 1992; Illingworth, 1993; Braesen et al., 1995). A variety of pathological conditions such as ischemia/ hypoxia and oxidative stress can lead to ERS, and excessive ERS can cause endothelial cell injury. Whether the ERS process can be inhibited by probucol thereby reducing endothelial cell injury has not been reported yet. In this study, we treated cultured human umbilical vein endothelial cells (HUVECs) with sodium dithionite in vitro, to establish a hypoxia/reoxygenation (H/R) injury model and then detect whether there has been ERS. Using treatment groups with different concentrations of probucol, we determined the activity of the HUVECs, the lactate dehydrogenase (LDH) activity of the cell culture medium, and the expression level of proteins such as GRP78, XBP-1, CHOP/ GADD153, etc., to study whether probucol suppresses ERS and whether this effect is concentration-dependent. Thus, we inferred the protective mechanisms of probucol in vascular endothelial cells, and provided a new theoretical basis for targeting prevention and treatment of AS.

\section{MATERIAL AND METHODS}

\section{Cells and reagents}

HUVECs were purchased from Shanghai Bogoo Biotechnology (Bogoo, SHH, China). Fetal bovine serum (FBS), 1640 medium, and trypsin (containing EDTA) were purchased from the Hyclone Company (Logan, UT, USA). Probucol, tetrazolium (MTT), and dimethyl sulfoxide (DMSO) were purchased from Sigma (Sigma-Aldrich, Oakville, CA, USA). LDH assay kits were obtained 
from Pierce Biotechnology (USA). RIPA lysis buffer strong, BCA protein assay kit, antibody dilution, and SDS-PAGE Sample Loading Buffer (5X) were purchased from Beyotime Biotechnology (Beyotime, SHH, China). Rabbit anti-GRP78 monoclonal antibody, rabbit anti-XBP-1 monoclonal antibody, and mouse anti-CHOP/GADD153 monoclonal antibodies were purchased from CST (Beverly, MA, USA). Horseradish peroxidase (HRP)-conjugated goat anti-mouse antibody and HRP-conjugated goat anti-rabbit antibody were supplied by ZSGB-BIO (Beijing, China). Polyvinyl difluoride membrane (PVDF; $0.45 \mu \mathrm{m}$ ) was purchased from Millipore (Billerica, MA, USA).

\section{Cell culture, hypoxia/reoxygenation, and treatment of probucol}

HUVECs were maintained in RPMI 1640 medium supplemented with $10 \%$ heat-inactivated FBS and $100 \mathrm{U} / \mathrm{mL}$ penicillin and streptomycin at $37^{\circ} \mathrm{C}$ in a humidified atmosphere of $5 \% \mathrm{CO}_{2}$. The cultures were incubated every 2-3 days with the same medium. Hypoxia was induced by using $\mathrm{Na}_{2} \mathrm{~S}_{2} \mathrm{O}_{4}$, which scavenges $\mathrm{O}_{2}$ molecules in solution and reduces the oxygen tension to zero (Zhang and Eyzaguirre, 1999; Kou et al., 2005; Wang et al., 2011b). $\mathrm{Na}_{2} \mathrm{~S}_{2} \mathrm{O}_{4}$ solution (40 mM) was added into cell medium, which was in monolayer fusion or sub-fusion state to ensure that the final concentration of $\mathrm{Na}_{2} \mathrm{~S}_{2} \mathrm{O}_{4}$ was $4 \mathrm{mM}$. The cultures were incubated for $4 \mathrm{~h}$ at $37^{\circ} \mathrm{C}$ and $5 \% \mathrm{CO}_{2}$, causing hypoxia-induced damage. Then, the medium was replaced with normal medium for $12 \mathrm{~h}$ at $37^{\circ} \mathrm{C}$ and $5 \% \mathrm{CO}_{2}$. The cultured HUVECs were randomly divided into five groups: a control group; three groups pretreated for $2 \mathrm{~h}$ with different concentrations of probucol, followed by H/R: Prob $3 \mu \mathrm{M}+$ H/R group, Prob $9 \mu \mathrm{M}+\mathrm{H} / \mathrm{R}$ group, Prob $27 \mu \mathrm{M}+\mathrm{H} / \mathrm{R}$ group; and an H/R group. The H/R cycle for all groups was $4 \mathrm{~h}$ of hypoxia followed by $12 \mathrm{~h}$ of reoxygenation.

\section{Cell viability assay}

Cell viability was analyzed by the MTT assay. The cultured HUVECs were randomly divided into five groups as above described. Briefly, $100 \mu \mathrm{L}$ exponentially growing HUVEC suspensions (1 x $10^{4}$ cells) were seeded onto a 96-well plate; each group had six wells. Twenty microliters of MTT ( $5 \mathrm{mg} / \mathrm{mL}$ final concentration) was added to each well after H/R treatment. Then, the plates were incubated at $37^{\circ} \mathrm{C}$ for an additional $4 \mathrm{~h}$ to allow the MTT to form formazan crystals by reacting with the metabolically active cells. The MTT medium mixture was removed and the formazan crystals were dissolved in $150 \mu \mathrm{L} \mathrm{DMSO}$ at $37^{\circ} \mathrm{C}$ for $10 \mathrm{~min}$. The absorbance was measured by a microplate reader at $492 \mathrm{~nm}$. Cell viability was determined by the formula: cell viability $(\%)=(T-B) /(C-B) x$ $100 \%$, where $T$ represents the values of each treatment group, $C$ represents the values of the control groups, and $B$ represent the values of the blank control group. Each experiment was performed independently three times.

\section{LDH leakage rate assay}

Exponentially growing HUVEC suspensions $\left(1 \times 10^{6}\right.$ cells) were seeded onto a 24-well plate, each group were given three wells, and treated with H/R as previously described; the cell supernatants were collected. The LDH leakage rate in the supernatants was measured with an $\mathrm{LDH}$ assay kit, according to the kit instructions.

\section{Western blot analysis}

After treatment, the HUVECs were washed three times in ice-cold PBS. The total cell 
proteins were collected and lysed for 30 min on ice in RIPA buffer containing $1 \%$ protease inhibitor cocktail. We determined the protein concentration using a BCA protein assay reagent kit, and then added the loading buffer, followed by incubation at $100^{\circ} \mathrm{C}$ for $10 \mathrm{~min}$. The cellular proteins were separated by SDS-PAGE, and transferred to PVDF membranes. The membrane was then blocked with $5 \%$ nonfat milk containing $10 \mathrm{mM}$ Tris- $\mathrm{HCl}, \mathrm{pH} 7.5,150 \mathrm{mM} \mathrm{NaCl}$, and $0.1 \%$ Tween-20 for $1 \mathrm{~h}$ at room temperature and incubated with primary antibodies for $1 \mathrm{~h}$ at room temperature and overnight at $4^{\circ} \mathrm{C}$. The membranes were washed and then incubated with HRP-conjugated secondary antibodies for $1 \mathrm{~h}$ at room temperature. The protein immune-complexes were detected using an ECL chemiluminescence detection system. The intensity of the bands was obtained by densitometric analysis using Image $\mathrm{J}$ and the density of each band was normalized to that of $\beta$-actin.

\section{Statistical analysis}

All data are reported as means \pm standard deviation (means \pm SD). The statistical significance of the data was determined with one-way ANOVA combined with the Dunnett test for comparison between groups. $\mathrm{P}<0.05$ was considered statistically significant.

\section{RESULTS}

\section{H/R-induced HUVEC injuries}

The results from the MTT assay showed that the cell viability after H/R injury decreased significantly compared to that of the control group (50.99 vs $100 \%$, $\mathrm{P}<0.05$; Table 1 and Figure $1 \mathrm{~A})$. The LDH leakage rate was significantly greater in $\mathrm{H} / \mathrm{R}$ group than that of the control group $(242.56 \pm 20.37$ vs $108.16 \pm 24.68, \mathrm{P}<0.05$; Table 1 and Figure $1 \mathrm{~B})$.

Table 1. Cell viability and LDH leakage rate for each group of HUVECs (means $\pm S D, N=6$ ).

\begin{tabular}{l|c|c|c}
\hline Groups & OD $(490 \mathrm{~nm})$ & Cell viability $(\%)$ & LDH (U/L) \\
\hline Control & $1.005 \pm 0.044$ & - & $108.16 \pm 24.68$ \\
\hline Prob $3 \mu \mathrm{M}+\mathrm{H} / \mathrm{R}$ & $0.697 \pm 0.043$ & $61.98^{\text {*\# }}$ & $238.30 \pm 24.92^{*}$ \\
\hline Prob $9 \mu \mathrm{M}+\mathrm{H} / \mathrm{R}$ & $0.791 \pm 0.035$ & $73.52^{\star \#}$ & $203.30 \pm 26.99^{* \#}$ \\
\hline Prob $27 \mu \mathrm{M}+\mathrm{H} / \mathrm{R}$ & $0.861 \pm 0.040$ & $82.22^{\text {*\# }}$ & $179.33 \pm 18.13^{\text {*\# }}$ \\
\hline $\mathrm{H} / \mathrm{R}$ & $0.608 \pm 0.054$ & $50.99^{*}$ & $242.56 \pm 20.37^{*}$ \\
\hline
\end{tabular}

${ }^{*} \mathrm{P}<0.05$ compared with control, ${ }^{\#} \mathrm{P}<0.05$ compared with H/R. OD means optical density.
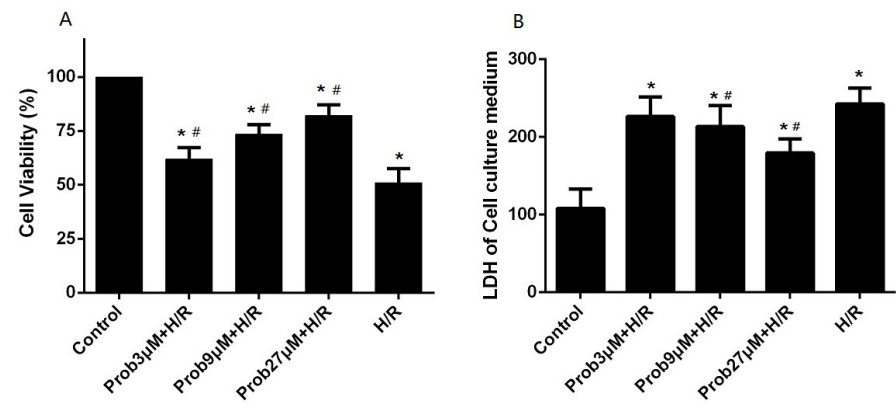

Figure 1. A. Cell viability of HUVECs treated with different concentrations of probucol following $H / R$ injury, as determined by MTT assay. B. LDH leakage rate from HUVECs for each group was detected by the LDH assay kit. *P $<0.05$ compared with control, " $\mathrm{P}<0.05$ compared with $\mathrm{H} / \mathrm{R}$. 


\section{Probucol protected HUVECs against H/R injury}

The cell viability after H/R injury increased significantly in the probucol-treated group compared with the other groups (Table 1 and Figure 1A). The LDH leakage rate following H/R injury decreased significantly after treatment with probucol (Table 1 and Figure 1B). The results indicate that probucol can decrease the impact of H/R injury on HUVECs. Furthermore, the protective effect of probucol is more obvious as its concentration is increased.

\section{Probucol inhibits the expression of H/R-induced GRP78}

To determine the effect of probucol on ERS induced by H/R, the expression of GRP78 was measured by western blot analysis. The result shows that the expression of GRP78 was highly upregulated after $\mathrm{H} / \mathrm{R}$, and probucol significantly decreased the level of GRP78 compared with $H / R$ injury alone (Figure 2), demonstrating that probucol has the ability to attenuate the ERS induced by $H / R$. Furthermore, as probucol concentration increases, the downregulation of GRP78 expression is more obvious.
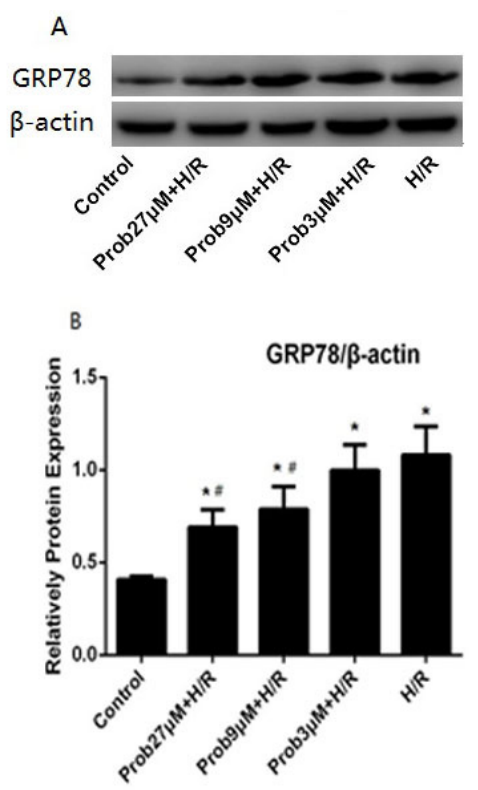

Figure 2. Western blot analysis of GRP78 protein expression in HUVECs $(\mathrm{N}=3)$. A. Expression of the GRP78 protein in HUVECs of each group; $\beta$-actin served as the internal control. B. Relative expression of GRP78 in HUVECs was analyzed. ${ }^{*} \mathrm{P}<0.05$ compared with control, ${ }^{\mathrm{P}}<0.05$ compared with $\mathrm{H} / \mathrm{R}$.

\section{Probucol attenuates the injury of HUVECs induced by $H / R$}

XBP-1 is a downstream ERS-associated protein of the UPR pathway. The level of XBP-1 significantly increased in the H/R group compared with that in the control group $(P<0.05$; Figure 3). However, the expression of XBP-1 significantly decreased in the probucol-treated groups, compared to that in the group with H/R injury alone. To investigate the role of probucol in reducing 
ERS-associated apoptosis, CHOP was also detected. The expression of CHOP was significantly upregulated in the H/R group compared with its expression in the control group. The expression of CHOP significantly decreased in the probucol-treated group compared with that of the H/R injury alone group. However, the levels of XBP-1 and CHOP significantly increased in all treated groups compared with their levels in the control group. The results demonstrated that probucol could reduce the apoptosis of HUVECs through attenuation of ERS induced by H/R. Furthermore, the downregulation of the expression of both XBP-1 and CHOP is more obvious as probucol concentration increases.

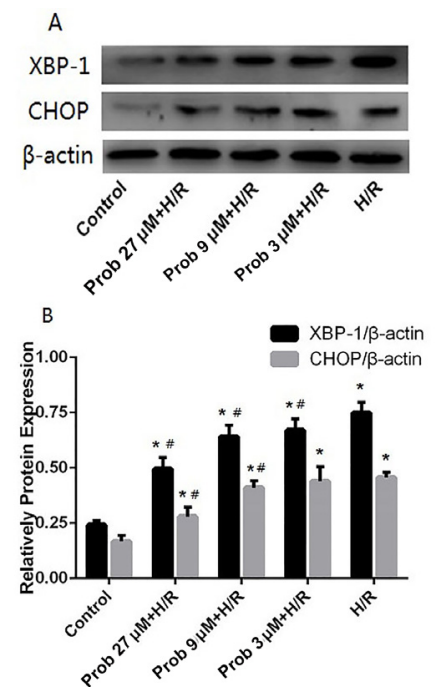

Figure 3. Western blot analysis of XBP-1 and CHOP protein expression in HUVECs $(\mathrm{N}=3)$. A. Expression of XBP-1 and $\mathrm{CHOP}$ proteins in HUVECs of each group; $\beta$-actin served as the internal control. B. Relative expression of XBP-1 and CHOP proteins in HUVECs. ${ }^{*} P<0.05$ compared with control, ${ }^{\# P}<0.05$ compared with $H / R$.

\section{DISCUSSION}

Probucol was first used clinically as a lipid-lowering drug in the 1970s; it is a synthetic antioxidant. Probucol inhibits the generation of oxygen-free radicals when vascular walls are injured, to inhibit the oxidative modification of LDL-C, to promote peroxide lipid transport and to eliminate AS plaques. It inhibits ox-LDL uptake by macrophages, prevents macrophage transformation into foam cells (Simon et al., 1993), and reduces the constant accumulation of lipids in AS plaques. Furthermore, probucol can inhibit vascular smooth muscle cell proliferation, thereby delaying the progression of AS and promoting the regression of plaque (Niimi et al., 2013; Chen et al., 2014). Studies have shown that probucol also improves the function of endothelial cells, inhibits endothelial cell apoptosis, and suppresses the expression of cell adhesion molecule, P-selectin, thereby increasing the content of nitric oxide (Zapolska-Downar et al., 2001). In this study, we used sodium dithionite with cultured HUVECs to establish an H/R injury model in vitro. The results show that the cell viability of HUVECs cultured in vitro significantly decreased and the LDH leakage rate of the cell culture medium significantly increased after H/R injury. However, the cell viability of HUVECs cultured in vitro significantly increased and the LDH leakage rate of the cell culture medium significantly decreased after intervention by probucol, indicating that probucol may exert a protective 
function on HUVECs against H/R injury. Whether this protective effect of probucol is due to its capability of regulating ERS has not been reported.

The ER is an important subcellular organelle where secretory and transmembrane proteins are synthesized. In addition to the post-translational modification and proper folding of proteins for normal functioning, the ER is also responsible for intracellular calcium homeostasis and lipid biosynthesis. Under pathological conditions, such as ischemia/hypoxia or oxidative stress, misfolded and unfolded proteins accumulate in the ER. These proteins cannot form normal disulfide bonds, causing the protein transport from the ER to the Golgi to be blocked and eventually increase the processing power of the ER, leading to ERS (Rutkowski and Kaufman, 2004; Wang et al., 2011a). A series of signal transduction pathways will be started, causing the UPR. Given a minor or transitory stimulation, the cells eventually restore homeostasis by UPR; however, under persistent or intense stimulation, the cells eventually entered an apoptotic program (Han et al., 2009; Kaufman et al., 2010; Scull and Tabas, 2011; Walter and Ron, 2011). GRP78 is a member of the heat-shock protein-70 family. As a characteristic chaperone of the ER, GRP78 is considered one of the marker proteins of ERS. Under normal conditions, GRP78 is in a non-activated state by binding to the three major pathways, protein inositol-requiring enzyme 1 (IRE1), protein kinase-like endoplasmic reticulum kinase (PERK), and activating transcription factor-6 (ATF6). When the cells were subjected to hypoxia, the ER environment became dysfunctional and GRP78 dissociated from PERK, IRE1, and ATF6, activating the UPR. In this study, we have analyzed the expression of GRP78 in $H / R$, in the presence and absence of probucol. The experiment demonstrated that the expression of GRP78 in HUVECs significantly increased after H/R injury, but significantly decreased upon treatment with probucol following $H / R$ injury. These results indicate that probucol may reduce the ERS induced by $H / R$.

X-box-binding protein 1 (XBP-1) is a protein that is associated with protein folding and endoplasmic reticulum construction. It is a transcription factor of UPR elements and can enhance the expression of some important downstream ERS proteins, including the ER chaperone GRP78 and the C/EBP homologous protein (CHOP), and also can induce the expression of ERAD-related genes (Yoshida et al., 1998; Gupta et al., 2010). CHOP, also known as growth arrest- and DNA damage-inducible gene 153 (GADD153), is a transcription factor that belongs to the C/EBP family. It is a key transcription factor of apoptosis downstream signaling pathways induced by ERS (Oyadomari and Mori, 2004). In non-stress conditions, its expression level is very low. While in ERS, three ways of UPR can induce the expression of the CHOP gene and promote the transcription of $\mathrm{CHOP}$ (Ma et al., 2002; Averous et al., 2004). CHOP can activate GADD34, ERO1, death receptor DR5, and other apoptotic reactive proteins. In addition, CHOP can inhibit the expression of anti-apoptotic BCL-2 gene and induce the formation of oxygen-free radicals and the depletion of intracellular glutathione, promoting cell damage, and increasing apoptosis (Oyadomari and Mori, 2004). We have analyzed the expression of XBP1 and $\mathrm{CHOP}$ in the presence and absence of probucol after treatment with $\mathrm{H} / \mathrm{R}$. The results showed that protein expression of XBP-1 and CHOP significantly increased after $\mathrm{H} / \mathrm{R}$ injury. As previously described, the viability of HUVECs cultured in vitro significantly decreased after $H / R$. The results showed that ERS is involved in the process of HUVEC injury, but the expression of XBP-1 and CHOP proteins significantly decreased after probucol treatment following H/R injury. Their viability was also significantly increased. These results provide substantial evidence that probucol can contribute to an effective inhibition of ERS induced by H/R.

In summary, by detecting cell viability, the LDH leakage rate, and the protein expression of GRP78, XBP-1, and CHOP, we observed the effects of the ERS response pathway induced by $H / R$. Results showed that the expression of ERS proteins significantly increased in HUVECs after 
being exposed to $H / R$, indicating that ERS was induced by $H / R$. We also observed that cell activity significantly increased, the LDH leakage rate significantly decreased, and the expression of ERSrelated proteins significantly decreased after probucol treatment following $H / R$ injury. These findings suggest that probucol may exert its protective effect on HUVECs through suppression of ERS induced by H/R. This is consistent with the theory that probucol can delay the progression of atherosclerosis. However, the signal transduction pathways through which probucol acts on ERS are still unclear. More study is needed to truly understand the relationship between probucol and ERS.

\section{Conflicts of interest}

The authors declare no conflict of interest.

\section{ACKNOWLEDGMENTS}

Thanks to all members of Pharmacology Laboratory of China Medical University who gave us a great help and support, which assured this experiment been done smoothly and successfully.

\section{REFERENCES}

Averous J, Bruhat A, Jousse C, Carraro V, et al. (2004). Induction of CHOP expression by amino acid limitation requires both ATF4 expression and ATF2 phosphorylation. J. Biol. Chem. 279: 5288-5297. http://dx.doi.org/10.1074/jbc.M311862200

Azfer A, Niu J, Rogers LM, Adamski FM, et al. (2006). Activation of endoplasmic reticulum stress response during the development of ischemic heart disease. Am. J. Physiol. Heart Circ. Physiol. 291: H1411-H1420. http://dx.doi.org/10.1152/ ajpheart.01378.2005

Braesen JH, Beisiegel U and Niendorf A (1995). Probucol inhibits not only the progression of atherosclerotic disease, but causes a different composition of atherosclerotic lesions in WHHL-rabbits. Virchows Arch. 426: 179-188. http://dx.doi. org/10.1007/BF00192640

Bredesen DE, Rao RV and Mehlen P (2006). Cell death in the nervous system. Nature 443: 796-802. http://dx.doi.org/10.1038/ nature05293

Chen Z, Li S, Zhao W, Chen X, et al. (2014). Protective effect of co-administration of rosuvastatin and probucol on atherosclerosis in rats. Can. J. Physiol. Pharmacol. 92: 797-803. http://dx.doi.org/10.1139/cjpp-2014-0169

Chiong M, Morales P, Torres G, Gutiérrez T, et al. (2013). Influence of glucose metabolism on vascular smooth muscle cell proliferation. Vasa 42: 8-16. http://dx.doi.org/10.1024/0301-1526/a000243

Fairn GD and Grinstein S (2008). Cell biology. A one-sided signal. Science 320: 458-460. http://dx.doi.org/10.1126/ science. 1158173

Goldschmidt-Clermont PJ, Dong C, Seo DM and Velazquez OC (2012). Atherosclerosis, inflammation, genetics, and stem cells: 2012 update. Curr. Atheroscler. Rep. 14: 201-210. http://dx.doi.org/10.1007/s11883-012-0244-1

Gupta S, Deepti A, Deegan S, Lisbona F, et al. (2010). HSP72 protects cells from ER stress-induced apoptosis via enhancement of IRE1alpha-XBP1 signaling through a physical interaction. PLOS Biol. 8: e1000410. http://dx.doi.org/10.1371/journal. pbio. 1000410

Han D, Lerner AG, Vande Walle L, Upton JP, et al. (2009). IRE1 alpha kinase activation modes control alternate endoribonuclease outputs to determine divergent cell fates. Cell 138: 562-575. http://dx.doi.org/10.1016/i.cell.2009.07.017

Illingworth DR (1993). The potential role of antioxidants in the prevention of atherosclerosis. J. Nutr. Sci. Vitaminol. (Tokyo) 39 (Suppl): S43-S47. http://dx.doi.org/10.3177/jnsv.39.Supplement S43

Kaufman RJ, Back SH, Song B, Han J, et al. (2010). The unfolded protein response is required to maintain the integrity of the endoplasmic reticulum, prevent oxidative stress and preserve differentiation in $\beta$-cells. Diabetes Obes. Metab. 12 (Suppl 2): 99-107. http://dx.doi.org/10.1111/j.1463-1326.2010.01281.x PubMed

Kou J, Yu B and Xu Q (2005). Inhibitory effects of ethanol extract from Radix Ophiopogon japonicus on venous thrombosis linked with its endothelium-protective and anti-adhesive activities. Vascul. Pharmacol. 43: 157-163. http://dx.doi. org/10.1016/j.vph.2005.06.004

Ma Y, Brewer JW, Diehl JA and Hendershot LM (2002). Two distinct stress signaling pathways converge upon the CHOP promoter during the mammalian unfolded protein response. J. Mol. Biol. 318: 1351-1365. http://dx.doi.org/10.1016/ $\underline{\text { S0022-2836(02)00234-6 }}$ 
Minamino T and Kitakaze M (2010). ER stress in cardiovascular disease. J. Mol. Cell. Cardiol. 48: 1105-1110. http://dx.doi. org/10.1016/j.yjmcc.2009.10.026

Niimi M, Keyamura Y, Nozako M, Koyama T, et al. (2013). Probucol inhibits the initiation of atherosclerosis in cholesterol-fed rabbits. Lipids Health Dis. 12: 166. http://dx.doi.org/10.1186/1476-511X-12-166

Oyadomari S and Mori M (2004). Roles of CHOP/GADD153 in endoplasmic reticulum stress. Cell Death Differ. 11: $381-389$. http://dx.doi.org/10.1038/sj.cdd.4401373

Pahl HL (1999). Signal transduction from the endoplasmic reticulum to the cell nucleus. Physiol. Rev. 79: 683-701.

Pirillo A, Norata GD and Catapano AL (2013). LOX-1, OxLDL, and atherosclerosis. Mediators Inflamm. 2013: 152786. http:// dx.doi.org/10.1155/2013/152786

Préda I, Bencze J and Vargova K (2005). [Endothelial function and ischemic heart disease]. Orv. Hetil. 146 (Suppl 2): $1047-1053$.

Riwanto M and Landmesser U (2013). High density lipoproteins and endothelial functions: mechanistic insights and alterations in cardiovascular disease. J. Lipid Res. 54: 3227-3243. http://dx.doi.org/10.1194/jlr.R037762

Rutkowski DT and Kaufman RJ (2004). A trip to the ER: coping with stress. Trends Cell Biol. 14: 20-28. http://dx.doi. org/10.1016/j.tcb.2003.11.001

Salisbury D and Bronas U (2014). Inflammation and immune system contribution to the etiology of atherosclerosis: mechanisms and methods of assessment. Nurs. Res. 63: 375-385. http://dx.doi.org/10.1097/NNR.0000000000000053

Schwartz CJ, Valente AJ, Sprague EA, Kelley JL, et al. (1992). Atherosclerosis. Potential targets for stabilization and regression Circulation 86 (Suppl): III117-III123.

Scull CM and Tabas I (2011). Mechanisms of ER stress-induced apoptosis in atherosclerosis. Arterioscler. Thromb. Vasc. Biol. 31: 2792-2797. http://dx.doi.org/10.1161/ATVBAHA.111.224881

Simon BC, Haudenschild CC and Cohen RA (1993). Preservation of endothelium-dependent relaxation in atherosclerotic rabbit aorta by probucol. J. Cardiovasc. Pharmacol. 21: 893-901. http://dx.doi.org/10.1097/00005344-199306000-00007

Walter P and Ron D (2011). The unfolded protein response: from stress pathway to homeostatic regulation. Science 334: 10811086. http://dx.doi.org/10.1126/science.1209038

Wang XQ, Yao RQ, Liu X, Huang JJ, et al. (2011a). Quercetin protects oligodendrocyte precursor cells from oxygen/glucose deprivation injury in vitro via the activation of the PI3K/Akt signaling pathway. Brain Res. Bull. 86: 277-284. http://dx.doi. org/10.1016/j.brainresbull.2011.07.014

Wang X, Eno CO, Altman BJ, Zhu Y, et al. (2011b). ER stress modulates cellular metabolism. Biochem. J. 435: 285-296. http:// dx.doi.org/10.1042/BJ20101864

Yoshida H, Haze K, Yanagi H, Yura T, et al. (1998). Identification of the cis-acting endoplasmic reticulum stress response element responsible for transcriptional induction of mammalian glucose-regulated proteins. Involvement of basic leucine zipper transcription factors. J. Biol. Chem. 273: 33741-33749.

Zapolska-Downar D, Zapolski-Downar A, Markiewski M, Ciechanowicz A, et al. (2001). Selective inhibition by probucol of vascular cell adhesion molecule-1 (VCAM-1) expression in human vascular endothelial cells. Atherosclerosis 155: 123130. http://dx.doi.org/10.1016/S0021-9150(00)00553-0

Zhang XQ and Eyzaguirre C (1999). Effects of hypoxia induced by Na2S2O4 on intracellular calcium and resting potential of mouse glomus cells. Brain Res. 818: 118-126. http://dx.doi.org/10.1016/S0006-8993(98)01249-9 